\title{
A crise de 1873 na Província da Bahia: efeitos internacionais sobre a recessão doméstica
}

The crisis of 1873 in the Province of Bahia: international effects on the domestic recession

\author{
Marcos Guedes Vaz Sampaio ${ }^{1}$
}

\section{Resumo}

Este artigo busca analisar a crise econômica de 1873, que se abateu sobre a Província da Bahia, oriunda, a princípio, de uma praga nos canaviais, afetando a produção da cultura açucareira baiana, mas que se desenvolveu, também, dentro de um ambiente de instabilidade internacional, que ficou conhecido como a "Grande Depressão" do século XIX. Esse período de recessão da economia mundial teve início no ano de 1873 e perdurou até 1896, abalando as principais nações do sistema internacional. Alvo de controvérsia no debate historiográfico em razão de não se constituir numa única crise, mas num período em que diversas crises ocorreram em diferentes países, a "Grande Depressão" reflete a instabilidade vivenciada pelo sistema internacional no último quartel do século XIX, em função da expansão do capitalismo de matriz liberal inglesa em um ambiente de acirramento da concorrência entre as nações que emergiam por meio da disseminação da industrialização. A conjunção de fatores internos e externos na análise da crise de 1873 na Província da Bahia reforça a compreensão de que o expansionismo sistêmico do capitalismo no transcurso do oitocentos penetrava cada vez mais nas diversas regiões do sistema mundial, resultando no aumento da influência de eventos internacionais nas dinâmicas domésticas.

Palavras-chave: Bahia. Crise internacional. Século XIX.

\section{Abstract}

This article seeks to analyze the economic crisis of 1873 , which occurred in the Province of Bahia, originally from a plague in the sugarcane plantations, affecting the production of the sugar culture of Bahia, but also developed in an environment of

\footnotetext{
${ }^{1}$ Doutor em História Econômica (USP) e Professor do Instituto de Humanidades, Artes e Ciências e do Programa de Pós-Graduação em Relações Internacionais da Universidade Federal da Bahia (UFBA).
} 
instability which became known as the "Great Depression" of the nineteenth century. This period of recession of the world economy began in the year 1873 and lasted until 1896 shaking the main nations of the international system. A target of controversy in the historiographical debate because it did not constitute a single crisis, but in a period where several crises occurred in different countries, the "Great Depression" reflects the instability experienced by the international system in the last quarter of the nineteenth century, due to the expansion of English liberal capitalism in an environment of increased competition among the nations that emerged through the spread of industrialization. The conjunction of internal and external factors in the analysis of the crisis of 1873 in the Province of Bahia reinforces the understanding that the systemic expansionism of capitalism in the course of the eighties penetrated more and more in the various regions of the world system, influence of international events on domestic dynamics.

Keywords: Bahia.International crisis. XIX century.

\section{Introdução}

A economia britânica alavancou e consolidou sua posição hegemônica no sistema internacional a partir da segunda metade do século XVIII. Vanguardista da era industrial, a Grã-Bretanha amplificou significativamente sua capacidade produtiva por meio de uma série de eventos que ficaram conhecidos como a Revolução Industrial. A preeminência inglesa se traduziu na construção de uma ordem internacional sob sua égide, que se disseminou por diversas regiões do mundo, submetendo-as aos seus interesses (ARRIGHI, 2006).

A expansão do seu modelo de capitalismo de matriz liberal visava facilitar a penetração de suas mercadorias e capitais em diferentes mercados. As nações principais do sistema internacional iniciaram seus processos de industrialização com atraso em relação à Grã-Bretanha, todavia, organizaram suas estruturas produtivas para enfrentar o capitalismo de matriz liberal inglesa pela via do protecionismo e intervencionismo estatal. A única exceção foi a França, que segundo Bairoch (2002) e Chang (2004), optou pelo liberalismo econômico, o que terminou por se refletir no seu atraso em relação às demais economias centrais.

A ascensão econômica da Alemanha, Estados Unidos, França, Holanda, Bélgica, Rússia e Japão, a despeito dos diferentes graus de industrialização em que se 
encontravam no último quartel do século XIX, contribuíram para acirrar as disputas internacionais por mais mercados. O capitalismo vivenciava um boom, fruto da sua expansão e disseminação industrial, bem como de um processo lento e gradual de formação monopolista de capital, resultante do acirramento da concorrência no cenário mundial (MAURO, 1976; PRADA, 1978; KRIPPENDORFF, 1979; BEAUD, 2004; HOBSBAWM, 1986; HOBSBAWM, 2004, LANDES, 1996).

A pujança econômica desse momento de expansão capitalista resultou em uma ampliação da oferta monetária para enfrentar o aumento da demanda e, como consequência desse movimento expansionista, ocorreu o recrudescimento dos movimentos especulativos. A predominância de preceitos liberais na dinâmica da economia doméstica dos Estados Nacionais resultava em mercados menos regulados, o que levava ao pulular de empresas sem lastro monetário, companhias com pouca capacidade de recursos que buscavam captá-los por meio da abertura de capitais nas bolsas de valores. O quadro especulativo ganhava contornos sombrios à semelhança do que ocorrera na economia estadunidense em 1857 (CALOMIRIS, SCHWEIKART, 1991; SAMPAIO, 2016).

É no âmbito desse panorama temerário que eclodirá a primeira de uma série de crises do último quartel do século XIX e que, em seu conjunto, ficaram conhecidas como a "Grande Depressão" do século XIX. Nome controverso no debate historiográfico, este período de importante instabilidade para o processo de expansão do sistema capitalista de matriz liberal inglesa, afetou de modos distintos e, em momentos diferentes, as mais importantes nações da economia mundial no período.

A Província da Bahia, região em declínio de importância econômica dentro do cenário doméstico da estrutura produtiva, comercial e financeira do Brasil, enfrentou nesse mesmo período, uma crise substancial na sua produção canavieira, cujo desdobramento foi sensível para o conjunto da economia provincial. O momento recessivo que o panorama internacional experimentava contribuiu para aprofundar a crise interna, bem como dificultar o seu movimento de recuperação, implicando numa análise de confluência de efeitos exógenos e endógenos na configuração do quadro depressivo baiano, para além da explicação meramente vinculada às questões internas.

$\mathrm{O}$ presente artigo pretende analisar os efeitos do quadro recessivo mundial e relacioná-lo com as questões em curso no ambiente doméstico que, somadas a essecenário depreciativo mais amplo, terminaram por provocar um dos momentos mais 
difíceis da história econômica da Bahia. Além desta introdução e das considerações finais, este artigo está subdividido em três tópicos. O primeiro centraliza sua atenção na análise do período recessivo internacional que ficou conhecido como a "Grande Depressão" do século XIX, o segundo aborda, de maneira panorâmica os efeitos sobre a economia brasileira e, por fim, o terceiro trata do caso da Província da Bahia, especificamente, e seu momento de convergência de efeitos regionais com internacionais que, em conjunto, contribuíram para agravar o quadro provincial.

\title{
A “Grande Depressão” do século XIX (1873-1896)
}

A "Grande Depressão" do século XIX, como é conhecida por um importante grupo de historiadores econômicos ${ }^{2}$, na verdade se configura como um conjunto de crises que ocorreram em diferentes países em momentos distintos dentro do intervalo cronológico que tem início no ano de 1873 e que termina em $1896^{3}$, podendo ser traduzido como um período de instabilidade sistêmica que envolve, praticamente, todo o último quartel do século XIX. Esse conjunto de crises contribuiu fortemente para abalar a crença no liberalismo econômico e recrudescer o discurso em defesa do papel intervencionista do Estado, mesmo entre setores do empresariado e demais agentes econômicos privados, como aponta Sklar apud Arrighi (2006, p. 295):

\begin{abstract}
Em meados de 1890, em meio à terceira longa depressão em três décadas sucessivas, difundiu-se na burguesia uma repulsa pelo mercado não regulamentado, em todos os grandes setores da economia. Quaisquer que fossem suas divergências programáticas, os agricultores, industriais, banqueiros e comerciantes, além dos já desencantados capitalistas ferroviários, encontraram um terreno comum na ideia de que a atividade competitiva de mercado, não regulamentada, resultava na produção de bens e serviços que - a preços que rendessem lucros razoáveis aos produtores dotados de eficiência normal ultrapassavam a demanda efetiva.
\end{abstract}

\footnotetext{
${ }^{2}$ A denominação é controversa, uma vez que historiadores como Eric Hobsbawm (2004), entendem que não houve um grande período recessivo dentro do sistema internacional sob parâmetros meramente econômicos. Para os que aceitam essa denominação, como Mauro (1976), Prada (1978), Krippendorff (1979), Beaud (2004) e Frieden (2008), o termo se aplica pelo longo período de instabilidade sistêmica em decorrência de crises importantes nos países centrais da economia-mundo oitocentista. Os autores deste artigo coadunam com esta interpretação, mas optaram por deixar o termo entre aspas pelo fato da denominação ser mais usualmente aplicada à Crise de 1929.

${ }^{3}$ O autor Michel Beaud (2004) se refere ao ano de 1895 como encerramento da "Grande Depressão", no entanto, todos os demais autores pesquisados tratam o ano de 1896 como o último relacionado ao período de instabilidade sistêmica do capitalismo no século XIX, de modo que os autores deste artigo optaram por este ano como baliza final da "Grande Depressão" do oitocentos.
} 
Kindleberger e Aliber (2013, p. 204-205) atribuem o início da crise de 1873 à indenização franco-prussiana paga em ouro, ainda no ano de 1871, o que levou ao aumento da especulação nos mercados alemão e austríaco, sobretudo após a emissão bancária alemã de 4 bilhões de marcos entre 1871 e 1873 (PRADA, 1978, p. 305). Somavam-se a isso, a excitação exagerada com a unificação alemã e a perspectiva de crescimento econômico em um ambiente de recrudescimento do sistema capitalista e da competitividade sob a influência do liberalismo inglês. Desse cenário inicial de euforia, em dois anos o quadro se transfigurou em depressão econômica, cuja origem foi o crack da bolsa de Viena, na Áustria, seguido de falências bancárias, tanto austríacas, quanto alemãs. Segundo Beaud (2004, p. 195), somente na Alemanha, a produção de ferro fundido registrou uma queda de $21 \%$ no ano de 1874 , enquanto seu preço despencou $37 \%$. Esta crise se espalhou afetando Itália, Holanda, Bélgica, Estados Unidos, GrãBretanha, França e Rússia (KINDLEBERGER, ALIBER, 2013, p. 205). Na economia estadunidense, por exemplo, o preço do ferro fundido caiu $27 \%$ entre 1873 e 1875. Combinando este quadro com o aumento na especulação, baixa oferta de mão-de-obra, alta dos custos e redução na rentabilidade em um cenário de expansão das estradas de ferro em torno de 50\% entre 1869 e 1873, o pânico se disseminou na bolsa provocando falências bancárias e de sociedades ferroviárias (BEAUD, 2004, p. 196).

$\mathrm{Na}$ Inglaterra, o primeiro setor a sentir os efeitos da eclosão da crise foi o exportador que vivenciou uma queda de $25 \%$ entre 1872 e 1875 e o recrudescimento no número de falências que, de um total de 7.490 em 1873, passou para 13.130 em 1879 (BEAUD, 2004, p. 196). Até o final do século XIX, a concentração dos capitais em poucas empresas se tornou realidade na Inglaterra, acompanhando um movimento que já existia na Alemanha (MAURO, 1976, p. 282). A retração econômica se verificou na queda dos preços combinada a uma elevação no desemprego, se constituindo num caso clássico de trade-off entre inflação e desemprego. O resultado foi uma crise de superprodução, fruto da expansão da produção e, consequentemente, da oferta, o que pressionou os preços para baixo, com a retração da demanda, em decorrência do desemprego. Como exemplo desse quadro experimentado pela economia inglesa, podese destacar o ramo produtor de trilhos para ferrovias que, de uma oferta de 2,5 milhões de toneladas, conseguiu vender em torno de 500 mil, com diminuição de $60 \%$ no seu preço entre 1872 e 1881 (BEAUD, 2004, p. 196). 
O desencadeamento desse período recessivo continuou com o crash da bolsa de Lyon no ano de 1882, seguido pela falência do Banco de Lyon e do Loire, além do Union Générale e inúmeras outras falências, tanto bancárias, quanto industriais. No ano de 1884 foi a vez de eclodir o "pânico das estradas de ferro" estadunidenses, fruto da ampliação da concorrência entre as companhias ferroviárias devido à alta nos preços do setor. O resultado foi falências bancárias, arrefecimento da atividade industrial, desemprego e queda de 15 a $22 \%$ nos salários do setor metalúrgico e de 25 a $30 \%$ nos salários do ramo têxtil (BEAUD, 2004, p. 197).

Nesse ínterim, a Alemanha passou a adotar medidas protecionistas e iniciou um processo de cartelização que culminou com 76 cartéis em 1885 (BEAUD, p. 197). A França, também, experimentou um processo de concentração de capitais, embora inferior ao vivenciado por ingleses, norte-americanos e alemães. A adoção do livrecomércio pelos franceses prejudicou sua expansão econômica, frente ao protecionismo alemão e ao avanço mais consistente da economia inglesa (MAURO, 1976). A GrãBretanha, por sua vez, sofreu as consequências da instabilidade desse período, que se tornava mais complexo, pelos rumos que a economia alemã estava tomando. O cenário envolvia crises, estreitamento das relações comerciais por medidas protecionistas, ampliação da concentração de capitais por formação de cartéis, acirramento na concorrência em diversos mercados com rebatimentos sobre o nível de preços, recrudescimento do desemprego, o que prolongou a depressão até o ano de 1887.

Notícias alvissareiras como a descoberta de ouro na África do Sul, o projeto francês no canal do Panamá, a expansão das linhas férreas nos Estados Unidos e as perspectivas econômicas favoráveis na Argentina, Austrália e Nova Zelândia rejubilaram o cenário internacional com novas expectativas de lucros. O momento de distensão, porém, durou pouco. Em 1889, a companhia francesa responsável pela construção do canal do Panamá, Société des Métaux, se envolveu numa ação especulativa com o cobre e foi à bancarrota, gerando pânico na bolsa, crise de crédito e um novo ciclo depressivo que resultou em mais um movimento protecionista. No ano seguinte, o Banco Baring Brothers foi vítima de uma crise de confiança por ser o agente financeiro da Argentina, que passou a enfrentar dificuldades econômicas e financeiras, além de vivenciar um quadro de instabilidade política doméstica (PRADA, 1978, p. 308). Embora o Banco da Inglaterra tenha agido rápido e, com auxílio de outros bancos, limitado a crise gerada pelo pânico, o setor têxtil algodoeiro inglês, bem como o ramo 
metalúrgico e de construção naval sofreram perdas comerciais em função dessa crise e de outras que assolaram os Estados Unidos, a Argentina e a Austrália no ano de 1893.

A economia norte-americana, por sua vez, enfrentou mais uma crise gerada no setor ferroviário devido à queda nas margens de lucro, o que desencadeou reflexos negativos na bolsa provocando a redução nas cotações das ações das companhias de estradas-de-ferro. Cerca de 491 bancos abriram falência, recrudescendo o desemprego e levando a diminuição da massa salarial (BEAUD, 2004, p. 198). A recuperação econômica ocorreu em um prazo relativamente curto, finalizando o período recessivo no final do ano de 1895 .

O conjunto das crises que eclodiram nesse intervalo de tempo revela uma característica comum: a diminuição no nível de preços, fruto da combinação de ampliação da oferta concomitante a uma contração da demanda. Isto se justificava pelo momento de expansão da produção, sobretudo industrial, fruto da disseminação da industrialização na Europa, associada a um ambiente de maior estímulo ao desenvolvimento tecnológico, o que aumentava a escala produtiva, combinada a um quadro de redução da massa salarial em decorrência do desemprego estrutural desta fase do sistema capitalista, em que a tecnologia reduzia postos de trabalho e o êxodo rural pressionava o mercado interno dos principais centros urbanos europeus (BEAUD, 2004; PRADA, 1978).

O período que abrange a "Grande Depressão" do século XIX pode ser analisado, portanto, como um momento de crise de superprodução, associada a um quadro de elevada atividade especulativa, fruto da formação de expectativas dos agentes econômicos diante da expansão substancial do sistema capitalista sob o domínio ideológico do liberalismo, combinado a obstáculos de natureza estrutural socioeconômica. A amplificação dos investimentos em tecnologia, em razão do aumento da competitividade internacional e as necessidades das empresas de recrudescerem as inversões, resultaram no aumento do desemprego e na pressão pela redução da massa salarial do operariado nas principais nações do oitocentos. Os limites da demanda em contraponto ao avanço da oferta por incremento da produtividade, sobretudo devido a uma melhor participação da tecnologia na função de produção, provocaram crises de superprodução, cujo desdobramento principal em cada uma delas foi a depressão do sistema de preços e a queda na rentabilidade das empresas, afetando 
os mercados de capitais das economias centrais, como consequência da interligação cada vez maior entre as mais destacadas praças mercantis e financeiras do século XIX.

Os impactos internacionais dos eventos oriundos desse modelo dinâmico gerador do conjunto de crises que envolveu o período em tela, desvelou maior magnitude à medida que a nação estivesse mais integrada ao sistema mundial. Países de inserção mais discreta, como o Brasil, foram menos afetados, contudo, também sofreram com os resultados desse período recessivo. Ao final dessa fase da história econômica mundial, poucos tinham a certeza se se tratou de uma grande crise pendular, que oscilou de país para país, prolongando a crise e transmitindo a impressão de que ela era um corpo único ou se se tratou de um período em que crises pulularam dentro do quadro mundial oitocentista, sem que grandes desencadeamentos as envolvesse dentro de uma leitura interpretativa que garantisse sua unicidade. De qualquer modo, apesar dos efeitos mais discretos, seria equivocado não analisar, ainda que de maneira panorâmica, os desdobramentos desse importante período para a compreensão do sistema internacional no último quartel do século XIX sobre o conjunto da economia brasileira.

\section{Um olhar panorâmico da economia brasileira no contexto da "Grande Depressão"}

O conjunto da economia brasileira, em linhas gerais, não sentiu de maneira muito significativa os efeitos do período de instabilidade sistêmica do capitalismo de matriz liberal inglesa no transcurso do último quartel do oitocentos. Ao menos, se comparado a outras nações periféricas, como a Argentina, onde a situação ficou calamitosa a ponto de se espalhar rumores de que declararia moratória, o que provocou a quebra do Banco Baring Brothers de Londres (FRIEDEN, 2008, p. 25), conforme mencionado anteriormente. Furtado (1998, p. 116-117) atribuiu a esse desempenho menos conturbado no Brasil, à política de desvalorização cambial praticada pelo governo brasileiro, que contribuiu para atenuar os efeitos domésticos da crise ampla de superprodução, por meio do estímulo ao setor exportador. O desdobramento adverso dessa política, por outro lado, foi o aumento do déficit orçamentário do governo que chegou a comprometer a capacidade do país saldar sua dívida externa, como nos revela Fausto (2006, p. 37):

A pedra angular do sistema econômico-financeiro herdado pela República consistia na exportação de produtos primários - geradora de divisas - e no controle dos instrumentos de câmbio como mecanismo básico para assegurar 


\begin{abstract}
a continuidade da produção exportadora, apesar das flutuações do preço e da demanda externos, bem como para financiar o gasto público, pois o imposto principal que cobria as despesas do Governo era o imposto às importações (em 1897 correspondeu a 73,5\% da renda arrecadada pelo Tesouro, e em 1898 a 67\%). [...] o Governo via-se às voltas com déficits crescentes diante da perda que sofria com a diminuição das importações e com os efeitos das desvalorizações sobre um imposto de importação que se pagava em taxa de câmbio fixa. Daí, por outro lado, novos empréstimos externos e, novamente, em espiral, crescimento do serviço da dívida.
\end{abstract}

O comportamento do déficit do balanço das finanças públicas do Império do Brasil, portanto, se constitui num importante indicador dos efeitos penosos das crises internacionais do período sobre o conjunto da economia brasileira. Embora o aumento no déficit não estivesse relacionado apenas ao ambiente externo, a arquitetura de funcionamento do Tesouro nacional atrelava fortemente seus resultados à conjuntura internacional. A concentração maior das receitas do país na arrecadação sobre o imposto de importação e a política de constantes desvalorizações cambiais, que tendiam a se acentuar em momentos de depressão externa, levavam a resultados mais desfavoráveis nos exercícios contábeis em anos de cenários mais nebulosos no exterior. Ademais, o dinamismo da economia brasileira estava intimamente relacionado ao desempenho da produção cafeeira, de modo que a política cambial agia em seu benefício, em detrimento do conjunto do país.

Frieden (2008, p. 25) apontou que a "Grande Depressão" do século XIX afetou particularmente os países da periferia do sistema-mundo na capacidade de pagamento das nações credoras. Como se viu, ele mencionou a debacle do Banco Baring Brothers de Londres, que era um dos maiores bancos de investimento da época, em decorrência dos rumores de que a Argentina daria um calote na sua dívida. Frieden relaciona essa situação da economia argentina aos efeitos da crise sistêmica internacional sobre suas finanças domésticas. Não há evidências, tampouco, estudos que indiquem que o Brasil tenha experimentado uma situação tão dramática no período. O que pode ser verificado, contudo, é a piora no desempenho das finanças públicas do Império, fruto, como visto, da política cambial de desvalorização em benefício do setor exportador, que trouxe prejuízos ao erário, mas que sofreu, também, com os impactos do ciclo recessivo da economia mundial, como mostra a Tabela 1 abaixo: 
Tabela 1. Balanço das receitas e despesas do Império do Brasil (1872-1886)

(em contos de réis)

\begin{tabular}{c|c|c|r|c}
\hline Exercício & Receita & Despesa & \multicolumn{1}{c|}{ Saldo } & $\begin{array}{c}\text { Variação do } \\
\text { Saldo (em \%) }\end{array}$ \\
\hline $1872-1873$ & 110.713 & 121.874 & -11.161 & - \\
\hline $1873-1874$ & 102.652 & 121.481 & -18.829 & $+68,7$ \\
\hline $1874-1875$ & 104.707 & 125.855 & -21.148 & $+12,3$ \\
\hline $1875-1876$ & 100.718 & 126.780 & -26.062 & $+23,2$ \\
\hline $1876-1877$ & 98.970 & 135.801 & -36.831 & $+41,3$ \\
\hline $1877-1878$ & 109.221 & 151.492 & -42.271 & $+14,8$ \\
\hline $1878-1879$ & 111.802 & 181.469 & -69.667 & $+64,8$ \\
\hline $1879-1880$ & 120.393 & 150.134 & -29.741 & $-57,3$ \\
\hline $1880-1881$ & 128.364 & 138.583 & -10.219 & $-65,6$ \\
\hline $1881-1882$ & 130.456 & 139.471 & -9.015 & $-11,8$ \\
\hline $1882-1883$ & 129.698 & 152.958 & -23.260 & $+158,0$ \\
\hline $1883-1884$ & 132.593 & 154.257 & -21.664 & $-6,9$ \\
\hline $1884-1885$ & 121.974 & 158.496 & -36.522 & $+68,6$ \\
\hline $1885-1886$ & 126.883 & 153.623 & -26.740 & $-26,8$ \\
\hline $1886-1887^{5}$ & 145.842 & 151.363 & -5.521 & $-79,4$ \\
\hline
\end{tabular}

Fonte: IBGE, 1990, p. 616. Tabela adaptada pelo autor.

A observação da tabela acima sobre as receitas e despesas do Império brasileiro no intervalo temporal entre 1872 e 1886 permite analisar que, a despeito do quadro problemático de déficits recorrentes no balanço das finanças públicas do Brasil, as variações nesse déficit foram mais significativas nos anos em que, coincidentemente, eclodiram as crises mais importantes do sistema internacional no período. No ano de 1873, por exemplo, quando eclodiu o crash da Bolsa de Viena, o déficit brasileiro aumentou $68,7 \%$ em relação ao ano anterior, tendo sido o segundo pior desempenho dentro da baliza cronológica em tela. $\mathrm{O}$ ano de 1882, cuja crise teve seu epicentro na economia francesa com a quebra da Bolsa de Lyon, registrou o maior crescimento relativo do déficit no período em análise, de aproximadamente, $158 \%$ ! O terceiro pior desempenho do período, de cerca de $68,6 \%$ de elevação no déficit do balanço financeiro do Império em relação ao exercício anterior, converge com outra crise importante da

\footnotetext{
${ }^{4}$ A baliza cronológica final foi escolhida para manter o padrão homogêneo de análise com o intervalo temporal obtido para a Província da Bahia.

${ }^{5}$ Os dados compilados pelo IBGE para o exercício 1886-1887 foram relativos a 3 semestres. Para evitar a distorção na análise comparativa dos números, os autores optaram por calcular a média simples e multiplicar o resultado por dois. Os valores de receita e despesa referentes a este exercício, portanto, se referem ao dobro da média calculada. A despeito de possíveis imprecisões, o resultado se aproxima do comportamento evolutivo, tanto no que se refere à receita, quanto à despesa.
} 
"Grande Depressão" do oitocentos, relacionada ao pânico das estradas-de-ferro norteamericanas, que eclodiu no ano de 1884.

A coincidência entre a piora no desempenho das finanças públicas imperiais e o estopim das principais crises do período de maior instabilidade do sistema internacional no século XIX, certamente, não é fruto do acaso. Todos os exercícios contábeis relacionados às crises apresentam alguma queda nas receitas e aumento ou manutenção no nível de despesas. A queda nas receitas tem relação com a retração econômica e a redução no volume de negócios, principalmente, de origem estrangeira, o que provoca uma diminuição na arrecadação do imposto sobre importações, principal fonte de renda do Império brasileiro. O aumento nas despesas, por outro lado, sofreu o impacto do aumento dos serviços da dívida, sobretudo, em razão da política de desvalorização cambial. O historiador Evaldo Cabral de Mello (1999) assim abordou os impactos da “Grande Depressão” oitocentista sobre a economia brasileira:

\begin{abstract}
Na esteira do craque, veio a 'grande depressão' (1873-1896), particularmente penosa para a economia inglesa. Para o programa brasileiro, ela resultou numa diminuição da disponibilidade de capitais e em dificuldades às nossas exportações, com repercussões previsíveis sobre o equilíbrio orçamentário e cambial. Em 1877, o Governo imperial reconhecia o impasse a que chegara a aplicação da lei 2450, ao observar que "os capitais estrangeiros não se têm prestado a empresas desta ordem", fosse "pela desconfiança geral que se manifesta atualmente em todas as praças da Europa", fosse "por qualquer outra causa" MELLO, 1999, p. 200).
\end{abstract}

Segundo a historiadora Nícia Vilela Luz (2004, p. 49), a Crise de 1875, uma das mais importantes para a história econômica brasileira do século XIX, foi fruto dos efeitos retardatários da "Grande Depressão" que acometeu o sistema internacional. Embora pareça pouco crível que os desdobramentos do crash da Bolsa de Viena sobre os mercados austríaco e alemão em 1873 só atingiram o Brasil dois anos depois, o que uma leitura atenta sobre o período permite contrapor a essa interpretação é de que os desdobramentos foram imediatos, isto é, foram sentidos no mesmo ano do estopim da crise, porém, os efeitos se prolongaram favorecendo ao surgimento de um quadro de exacerbação recessiva no Brasil, no ano de 1875, devido a fatores domésticos combinados ao cenário externo mais instável. Por isso, é interessante observar que ela afirma que o país, a partir desse evento, entrou "num longo período de mal-estar econômico", como se pode observar: 
[...] a depressão econômica que já atingira os países industrializados e que, em 1875 alcançaria o Brasil onde a manifestação mais espetacular da crise foi a falência de vários estabelecimentos de crédito, dentre eles o Banco Nacional e o Banco Mauá. O país entraria num longo período de mal-estar econômico, ora atenuando-se, ora agravando-se, principalmente com a crise cafeeira de 1880-1886, mal-estar este que seria um fator decisivo no desenvolvimento do nosso nacionalismo econômico (LUZ , 2004, p. 49),.

Dito de outra forma, a Crise de 1875 que aconteceu no Brasil foi provocada pelos efeitos do crash da Bolsa de Viena e dos seus desdobramentos sobre o sistema internacional ainda no ano de 1873. O fator mais relevante como reforço dessa interpretação foi a escassez de capitais nas principais praças do país, tanto pela inibição da política emissionista, que vigorara até então, quanto pelo deslocamento do numerário em poder do público ou dos bancos comerciais para o Tesouro, devido a um aumento na rentabilidade dos títulos ou, ainda, pelos saques em favor dos mercados europeus em crise. Conforme demonstram Mont'alegre (1972, p. 201-203) e Peláez e Suzigan (1981, p. 118-120), o estopim da Crise de 1875 foi a moratória do Banco Nacional, o terceiro em importância na capital do Império, abaixo apenas do Banco do Brasil e do Banco Rural e Hipotecário. Os eventos que levaram a isso, contudo, começaram um pouco antes, mais precisamente no final do ano de 1873 , tendo sido agravados no decorrer do ano de 1874.

Um indicador importante que reforça esta linha de interpretação é o volume de papel-moeda em poder do público, pois se refere à liquidez da economia. Quando se observa este indicador, nota-se que em 1871, seu montante era de 188,1 mil contos de réis. Em 1873, este volume caiu para 174,9 mil contos de réis, o que representa uma contração de, aproximadamente, 7\%. No ano de 1875, o padrão de queda continuou, reduzindo o montante para 164,5 mil contos de réis, o que significa uma diminuição total de cerca de 12,5\% em relação ao ano de 1871(IBGE, 1990, p. 528). Ou seja, a escassez de capitais em poder do público já se verificava desde 1873, ano de eclosão da primeira crise internacional do período da "Grande Depressão" oitocentista, mas persistiu, agravando o quadro dois anos depois.

Quando se verifica os outros dois anos emblemáticos para o período em análise, os anos de 1882 e 1884, em função das crises francesa e estadunidense, também houve uma redução do papel-moeda em poder do público em relação ao montante total. Se para o ano de 1873, o percentual de papel-moeda em poder do público em relação ao total era de, aproximadamente, 94,5\%, no ano de 1882, este percentual diminuiu para $91,1 \%$, enquanto que, no ano de 1884 , a retração se acentuou, chegando a $89,7 \%$. A 
contração monetária do papel-moeda em poder do público em 1884 foi, inclusive, maior do que em 1875, que como visto, foi o ano em que ocorreu um dos episódios mais importantes de pânico no mercado financeiro brasileiro. Ora, a verificação desses dados permite concluir que a "Grande Depressão" do século XIX produziu efeitos negativos sobre o conjunto da economia brasileira, podendo ser destacados o aumento no déficit do Tesouro do Império e a contração no volume de meio circulante em poder do público.

A coincidência, portanto, que se verifica entre os anos de ampliação do déficit e os anos de crises mais agudas no cenário internacional, bem como o comportamento do papel-moeda em poder do público que sofreu contrações de magnitudes variadas nesses mesmos anos, reforçam o entendimento de que, a despeito dos impactos terem sido inferiores a outras nações periféricas, não devem ser desprezados. Não obstante, cumpre acrescentar que a análise dos efeitos desse emblemático período para a história econômica mundial sobre a estrutura produtiva, comercial e financeira do Brasil, necessita, sem sombra de dúvidas, de outros estudos que possam contribuir para uma melhor avaliação dos impactos domésticos provocados pela "Grande Depressão" do oitocentos.

\section{Crise e recessão na Província da Bahia: fatores endógenos e exógenos}

A Província da Bahia experimentou um movimento de recessão econômica doméstica, no mesmo período que compreendeu a "Grande Depressão" do século XIX. Diversos estudiosos que se debruçaram sobre o tema, como Waldemar Mattos (2011), Luís Henrique Dias Tavares (2001), Francisco Marques de Góes Calmon (1979) e Kátia Mattoso (2004), apontaram, quase que exclusivamente, fatores endógenos para explicar o período recessivo enfrentado pela economia baiana. Os poucos fatores exógenos, quando elencados, não possuem relação com a época conturbada que o cenário econômico mundial atravessava. Somente Kátia Mattoso (2004) atribuiu alguma contribuição da “Grande Depressão” para o quadro recessivo da província.

Calmon (1979, p. 108-109), por exemplo, afirma que o período recessivo da economia baiana teve início em 1873 e prosseguiu até o ano de 1890. Elenca como fatores responsáveis por esse momento adverso para a Província da Bahia a seca de 1859, a queda nas exportações de diamantes, a baixa na cultura algodoeira, a melhoria do açúcar estrangeiro, aumentando a concorrência, os prejuízos da cultura fumageira 
por carência de capitais para investimentos, falta de cereais pela irregularidade climática, o que favoreceu o incremento das importações e, por fim, o intercâmbio de escravos para o sul do país. Mattos (2011, p. 92), assim como Calmon (1979), estende o momento depressivo da economia provincial até o ano de 1890 e enumera os mesmos motivos apontados por este para justificar o período recessivo da economia provincial. Cumpre notar que o intervalo apresentado por ambos, aproxima-se substancialmente do período da recessão mundial, isto é, de 1873 a 1896.

Tavares (2001, p. 287) limitou-se a justificar que o período de crise que a Província atravessou tinha relação com a má qualidade do açúcar baiano, mercadoria principal da sua pauta de exportações, mas, também, com a perda de mão-de-obra escrava para a região Sudeste. Mattoso (2004, p. 102), por sua vez, argumenta que o intervalo cronológico que começou em 1860, prolongando-se até 1887, pode ser caracterizado como uma fase B do ciclo de Kondratieff. Os motivos seriam os efeitos deletérios da Guerra do Paraguai (1865-1870), a crise agrícola do algodão, a praga da cana-de-açúcar, a concorrência dos diamantes do Cabo, a intensificação do êxodo da mão-de-obra para o sul do Brasil, a abolição da escravidão, a dificuldade de crédito, as secas e a "Grande Depressão" de 1873.

A baliza cronológica apresentada por Mattoso (2004) para a fase recessiva da economia baiana, de 1860 a 1887, apresenta alguma convergência temporal com a “Grande Depressão”, embora menor que a dos outros autores. De qualquer modo, sua baliza, igualmente, envolve os anos em que ocorreram as três principais crises do período, que foram as de 1873, 1882 e 1884, abrangendo, portanto, os eventos mais importantes para a compreensão do quadro depressivo mundial. Diante da percepção de que existe uma aproximação temporal entre o momento recessivo da economia baiana e o quadro de instabilidade sistêmica do capitalismo internacional no último quartel do oitocentos, uma questão se impõe: a fase depressiva baiana tem relação com a recessão internacional? Como a maioria dos estudos sobre esse período na Bahia atribuem, quase que, exclusivamente, a fatores domésticos o período de declínio econômico regional, mencionando a "Grande Depressão" apenas tangencialmente, como no caso de Kátia Mattoso (2004), torna-se relevante analisar se os fatores exógenos tiveram um papel 
mais importante do que o abordado pela historiografia sobre a economia baiana no século XIX ${ }^{6}$.

Este artigo parte da hipótese de que o cenário recessivo internacional provocou mais efeitos sobre a economia da Província da Bahia do que a historiografia tradicional analisou. Sem se descurar do entendimento de que a economia local tem sua dinâmica própria e que, provavelmente, os resultados inferiores produzidos pela estrutura produtiva interna no decurso do período em análise, desde seu início com a crise de 1873 até o ano de 1894, foram em sua maioria, causados por fatores endógenos, este estudo afirma que o panorama mundial de recessão que atingiu os principais países do sistema internacional provocou impactos mais substantivos do que a narrativa mais tradicional pressupõe.

No ano de 1873, por exemplo, os Estados Unidos, também, enfrentaram uma crise interna, inicialmente atribuída a fatores endógenos, mas que foram identificadas conexões com a "Grande Depressão", como na mudança dos investimentos alemães nas ferrovias estadunidenses, subitamente interrompidos após a eclosão da crise austríaca (KINDLEBERGER, ALIBER, 2013, p. 205). O desempenho da própria economia brasileira, como se viu, embora não tenha sofrido de maneira mais significativa as consequências da recessão mundial, se comparado com algumas nações, igualmente, apresentou impactos relacionados ao momento conturbado dentro do sistema-mundo

É inegável que a crise da economia açucareira teve causas locais pelas evidências de sua origem numa praga que atingiu as plantações de cana-de-açúcar afetando, sobremaneira, sua produtividade. A situação se agravou com o aumento da oferta mundial de açúcar, o que levou ao acirramento da concorrência e a queda nos preços. A irregularidade do clima também prejudicou a produção, tornando o quadro ainda mais complexo. Segundo Mattos (2011, p. 101), a economia baiana só começou a se recuperar a partir de 1891. Tavares (2001, p.286-287) afirmou que a crise não se restringiu ao açúcar, afetando também o fumo, o café e o algodão. O presidente da Província Antônio Cândido da Cruz Machado, segundo Tavares, responsabilizou o desequilíbrio climático e a escassez de recursos financeiros, o que o autor contesta, imputando a responsabilidade à má qualidade do açúcar produzido na Bahia.

\footnotetext{
${ }^{6}$ À exceção de MATTOSO (2004), que trata superficialmente do assunto, TAVARES (2001), MATTOS (2011), CALMON (1979), AZEVEDO, LINS (1969) e OLIVEIRA (1999) não atribuem importância ao período de instabilidade sistêmica do capitalismo nos resultados inferiores da economia da Província da Bahia dentro da baliza cronológica em tela.
} 
Ao observar algumas das causas apresentadas para a crise que a província experimentou, pode-se analisar que a praga, isoladamente, não foi responsável pelo momento de depressão econômica que a Bahia atravessou, mas, certamente, foi o principal fator. Eventos climáticos instáveis, por sua vez, sempre foram característicos da região, mas nem por isso, a Província viveu um período recessivo tão prolongado, o que fragiliza esse argumento. A princípio, o que melhor delineia o conjunto de fatores que colaboraram para a fase recessiva que a estrutura produtiva, comercial e financeira da Bahia enfrentou entre os anos de 1873 e 1890 foi a praga dos canaviais, a escassez de recursos financeiros, o atraso tecnológico da produção açucareira doméstica, a perda de braços para o sul do país, a ampliação da oferta internacional de açúcar, que depreciou os preços e a retração dos principais mercados mundiais pelos efeitos do cenário recessivo fruto da "Grande Depressão" do século XIX. Mattoso (2004, p. 102-103), inclusive, reconhece que a fase de recuperação da economia baiana, no período entre 1887 e 1897 se deu, dentre outros fatores, pela melhoria dos preços agrícolas no mercado internacional e acrescentou:

\begin{abstract}
A estreita dependência que a Bahia teve, e tem, dos mercados externos a partir da época colonial foi desfavorável à economia baiana. Foi acentuado seu papel de exportador de produtos primários e de importador de alimentos e de produtos industrializados, posição extremamente desfavorável para qualquer economia. Essa dependência se agrava pela depreciação progressiva e contínua da moeda brasileira e se reflete no comportamento dos preços locais durante o período considerado. A irregularidade das flutuações dos preços dos produtos de importação e exportação, impossíveis de controlar ou de prever na conjuntura geral do período, pode explicar a impossibilidade de constituição de reservas locais de capitais. Na falta de capitais, não era possível dirigir qualquer investimento para atividades produtivas, agrícolas ou industriais, o que acentuou a erosão da economia local (MATTOSO, 2004, p. 102-103).
\end{abstract}

Atenta-se para o fato de que a escassez de capitais ou de numerário, como aparece em diversos documentos, queixa comum presente nos relatórios dos presidentes da província, tem relação com a instabilidade econômica e financeira vivenciada pelo sistema internacional. Embora em poucos trechos dos relatórios e falas dos presidentes da província essa vinculação apareça, fica evidente sua relação direta de causalidade, como se verifica no relatório do Presidente da Província da Bahia, desembargador Henrique Pereira de Lucena (1877, p. 59/60):

Para acudir a instantes necessidades da lavoura promulgou o governo diversas leis, resoluções e decretos autorisando a creação de estabelecimentos 
de credito e de engenhos centraes com garantia de juros. Os primeiros não se puderão ainda estabelecer. Algumas concessões se fizeram para o estabelecimento de engenhos centraes n'esta Provincia: nenhum d'elles porém teve ainda lugar, lutando os respectivos concessionários com os embaraços provenientes da desconfiança geral e do retrahimento de capitaes na Europa.

Os desdobramentos do período recessivo do sistema econômico internacional se fizeram sentir na estrutura produtiva, comercial e financeira da Província da Bahia como elementos de amplificação e prolongamento da crise doméstica. Desse modo, a diversificação das mercadorias atingidas, bem como a magnitude dos efeitos sobre a produção interna são fatores constitutivos do conjunto de interpretação dos efeitos da "Grande Depressão" oitocentista sobre a economia baiana. Como mencionado anteriormente e aqui reforçado, a queda no desempenho econômico provincial, a despeito dos inegáveis fatores endógenos, se revelam mais intensos pelo prolongamento e extensão, extrapolando a questão da redução na produtividade da cultura açucareira. A generalização da crise afetando as exportações de algodão, fumo, café, dentre outros, bem como a escassez de capitais fortalecem o entendimento de que a retração das relações comerciais internacionais pelos efeitos mais substanciais da "Grande Depressão" sobre as nações centrais se estendeu sobre as demais economias do sistema internacional afetando, em graus diferentes de intensidade, praticamente todos os países integrados à dinâmica do sistema capitalista.

Regiões como a Província da Bahia, mesmo sendo pertencentes a países periféricos dentro da divisão internacional do trabalho, já se encontravam inseridas ao sistema-mundo capitalista e, portanto, se ressentindo dos seus efeitos. Quanto maior a integração às correntes internacionais de comércio, mais intensos eram os efeitos. $\mathrm{O}$ próprio prolongamento da crise doméstica e o declínio do desempenho provincial ao longo dos anos dentro do universo temporal da "Grande Depressão" oitocentista serve de reforço à interpretação de que os desdobramentos do cenário recessivo mundial foram mais significativos do que a atribuição dada pela narrativa tradicional. Os números do setor exportador baiano contribuem para reforçar esta compreensão, como pode ser constatado na Tabela 2. 
Tabela 2. Evolução das exportações baianas entre 1872 e $1886^{7}$

\begin{tabular}{c|c}
\hline Exercício & Exportação (em mil réis) \\
\hline $1872-1873$ & $17.963: 637 \$ 000$ \\
\hline $1873-1874$ & $12.778: 606 \$ 000$ \\
\hline $1874-1875$ & $15.743: 129 \$ 000$ \\
\hline $1875-1876$ & $15.037: 852 \$ 000$ \\
\hline $1876-1877$ & $15.992: 826 \$ 000$ \\
\hline $1877-1878$ & $16.452: 060 \$ 000$ \\
\hline $1878-1879$ & $16.347: 200 \$ 000$ \\
\hline $1879-1880$ & $18.130: 800 \$ 000$ \\
\hline $1880-1881$ & $15.007: 984 \$ 000$ \\
\hline $1881-1882$ & $16.285: 317 \$ 000$ \\
\hline $1882-1883$ & $11.942: 070 \$ 000$ \\
\hline $1883-1884$ & $15.844: 529 \$ 000$ \\
\hline $1884-1885$ & $13.951: 026 \$ 000$ \\
\hline $1885-1886$ & $15.149: 655 \$ 000$ \\
\hline $1886-1887$ & $14.838: 332 \$ 000$ \\
\hline
\end{tabular}

Fonte: BAHIA, 1978c. (Tabela adaptada pelos autores)

Os números das exportações baianas no intervalo de tempo em tela evidenciam um comportamento da demanda mundial convergente ao quadro recessivo da "Grande Depressão" do oitocentos. Destacam-se os exercícios de 1873-1874, 1882-1883 e 18841885, pois todos eles, como se viu, representam anos de estopim de alguma crise internacional: o primeiro exercício corresponde ao ano do crack da Bolsa de Viena que teve desdobramentos significativos sobre o sistema bancário austríaco e alemão, estendendo seus efeitos sobre as principais economias da época, como a Inglaterra, França, Rússia e Estados Unidos, dentre outros. Como este exercício, especificamente, também representa o início da crise açucareira baiana pela infestação de uma praga nos canaviais, o desempenho inferior pode ser atribuído a esta causa, no entanto, sem se descurar do que ocorria nas principais nações. Cumpre lembrar que os Estados Unidos, igualmente, enfrentaram uma crise doméstica no ano de 1873 relacionada à escassez de capitais, concomitante ao evento de maior amplitude que eclodira no império AustroHúngaro (KINDLEBERGER, ALIBER, 2013, p. 120).

O segundo exercício não possui qualquer referência substancial de algum evento doméstico de proporções tão importantes a ponto de provocar um declínio de, aproximadamente, $27 \%$ no volume das exportações em relação ao exercício anterior. Nesse período, entretanto, ocorreu a segunda grande crise internacional desse momento

\footnotetext{
${ }^{7}$ A baliza inicial escolhida foi o ano de 1872 para servir como referência por ser o ano imediatamente anterior à eclosão das crises doméstica e internacional. O intervalo cronológico se estende até 1886 por que as fontes consultadas não apresentam os dados sobre exportação para exercícios posteriores.
} 
de depressão mundial, em decorrência da quebra da Bolsa de Lyon, cujos efeitos se disseminaram pelos segmentos bancário e industrial, atingindo as economias alemã e inglesa.

No terceiro exercício contábil em destaque, o período entre 1884 e 1885, ocorreu a crise das estradas-de-ferro estadunidenses e, coincidentemente, houve mais uma queda no volume das exportações baianas, embora menos acentuada. Independentemente dos resultados desfavoráveis mais significativos se situarem, exatamente, nos mesmos anos de três das principais crises da "Grande Depressão" do século XIX, pode-se observar, igualmente, a diminuição no desempenho das exportações da Província da Bahia que, ao longo do intervalo cronológico analisado na Tabela 2, somente conseguiu superar o montante registrado no exercício imediatamente anterior ao início da crise, no período de 1879-1880, quando alcançou a cifra de 18.130:800\$000 réis aproximadamente.

Como se sabe que a crise dos canaviais não se prolongou por tanto tempo, tampouco a instabilidade climática perdurou por período tão longo, pode se inferir que a influência dos fatores exógenos relacionados ao momento recessivo do panorama internacional contribuiu de maneira evidente para a depreciação nos resultados das exportações baianas, ainda que não seja atribuído a este quadro responsabilidade por este desempenho. A má qualidade do açúcar baiano e o aumento da concorrência internacional, inegavelmente, contribuíram fortemente para a queda nas exportações, mas o cenário de retração na demanda dos países centrais e a insegurança que o quadro recessivo mundial provocou nas transações comerciais e financeiras auxiliam substancialmente na compreensão da escassez de capitais e de queda no volume da corrente internacional de comércio.

O movimento das exportações da Província da Bahia, como pode ser constatado, se manteve sempre abaixo do registrado no exercício 1872-1873, com a exceção, conforme mencionado, do período de 1879-1880. No intervalo entre 1873 e 1878, a média das exportações baianas foi de 15.391:945\$000 réis, o que equivale dizer que, no período ora em análise, as exportações se mantiveram, em média, 14\% abaixo do patamar atingido um ano antes do estouro da crise doméstica e mundial. Embora os documentos pesquisados não apresentem dados referentes às exportações baianas após o exercício de 1886-1887, a historiografia tradicional afirma que houve uma recuperação da economia baiana, encerrando, nas palavras da historiadora Kátia Mattoso (2004, p. 102), a fase B do ciclo de Kondratieff: 
1887-1897: recuperação - Nota-se uma certa reanimação da economia baiana, ligada às seguintes condições: (a) melhoria dos preços agrícolas no mercado internacional; (b) exportação do cacau, cujo volume e preço tomam marcha ascendente; (c) exportação de borracha de maniçoba e de carbonados, que alcançam preços compensadores no mercado externo; (d) "encilhamento", que multiplica as possibilidades de crédito.

Embora o período de instabilidade sistêmica internacional tenha se prolongado até o ano de 1896, a última crise de maior proporção ocorrera em 1884, portanto três anos antes do fim da fase de recessão da economia baiana, se for utilizada como referência a baliza cronológica apresentada por Kátia Mattoso. Ora, o primeiro fator elencado pela historiadora para justificar o fim do ciclo recessivo baiano foi a melhoria nos preços internacionais dos produtos agrícolas em geral. Como se sabe, a queda no nível geral desses preços se deu em função da "Grande Depressão" do século XIX. Prada (1978, p. 303) afirma que o intervalo temporal de depreciação no nível de preços abrange de 1873 a 1886, dando sinais de recuperação após este período, coincidindo com a leitura de Mattoso para a Província da Bahia. Essa coincidência cronológica pode ser verificada a partir do trecho abaixo extraído da obra de Prada (1978, p. 307):

A partir de 1886 em todo o mundo se notam sintomas de recuperação e se inicia um movimento de alta conjuntura, no qual influem o ouro do Transval e o silver rush australiano (1888). Em Londres a indústria e o comércio reactivaram-se e o investimento de capitais dirige-se amplamente para a América do Sul (Argentina, sobretudo).

A relação temporal entre o fim do período recessivo baiano e o início da recuperação mundial após a "Grande Depressão" evidencia a influência que a fase depressiva da economia internacional teve sobre a Província da Bahia, a despeito da pouca atenção que a historiografia tradicional deu a este evento. O capitalismo expandia seu raio de ação dentro do sistema internacional integrando cada vez mais áreas externas ao seu campo de influência, ao mesmo tempo em que consolidava as regiões periféricas na esfera de ação dos países centrais, reforçando o processo histórico inaugurado nos primórdios da Idade Moderna com a expansão ultramarina de ampliação e consolidação do sistema-mundo de matriz capitalista. Os laços entre os mais diversos Estados nacionais se estreitavam, embora dividindo-os em países centrais, vetores dinâmicos do sistema, e periféricos, subordinados aos humores do centro dominante. $\mathrm{O}$ progresso econômico e técnico dos Estados nacionais mais importantes contribuiu para solidificar essa divisão, cristalizando o papel que cada um desempenharia dentro do 
sistema-mundo em expansão. No âmbito dessa dinâmica, as nações periféricas sofriam os desdobramentos das crises que se originavam no centro, como ocorreu com o Brasil. As províncias e regiões dos países periféricos, porém, poderiam sentir efeitos ainda maiores, a depender de suas particularidades no momento de eclosão das crises, como foi o caso da Bahia.

\section{Considerações finais}

A "Grande Depressão" do século XIX foi o nome dado por alguns historiadores para o período de instabilidade sistêmica experimentado pelo capitalismo de matriz liberal inglesa no transcurso dos anos de 1873 a 1896. O conjunto de crises internacionais importantes num intervalo de tempo significativo levou uma parte dos pesquisadores a interpretar que, naquele momento, dada à especificidade das crises, o mundo atravessava uma "Grande Depressão" que se refletiu no declínio do desempenho econômico das principais nações do oitocentos com desdobramentos significativos sobre os mais diversos mercados.

A maior ou menor integração ao sistema-mundo capitalista em expansão implicava em efeitos mais ou menos expressivos no ambiente doméstico de cada país. $\mathrm{O}$ Brasil sentiu os impactos do período recessivo, embora de maneira menos intensa do que outras nações periféricas, como a Argentina, por exemplo. No caso da Bahia, em função de uma fragilidade maior relacionada ao declínio do açúcar, enquanto o Brasil experimentava a ascensão da economia cafeeira, sentiu com mais força os efeitos da recessão mundial. Ainda assim, a historiografia tradicional deu pouca atenção aos desdobramentos da "Grande Depressão" sobre a economia provincial. A exceção foi o trabalho da historiadora Kátia Mattoso que fez uma referência à "Grande Depressão" do século XIX como um dos elementos responsáveis pelo advento da fase B do ciclo de Kondratieff na economia baiana no último quartel do oitocentos.

A observação de variáveis como o balanço das receitas e despesas do Império, o volume do meio circulante em poder do público e, no caso da Província da Bahia, o comportamento das exportações, permitiram chegar a uma compreensão maior dos efeitos deletérios do quadro recessivo internacional sobre o mercado interno brasileiro e, sobretudo, baiano. No caso do balanço das receitas e despesas do Império brasileiro no período, ficou evidente que na sequência de anos deficitários dentro do período em 
análise, o saldo negativo recrudesceu nos anos de eclosão das principais crises internacionais.

O padrão comportamental do papel-moeda em poder do público, por sua vez, não revelou simetria tão significativa, principalmente, devido à influência destacada da economia norte-americana sobre as exportações de café do Brasil. Na condição de principal produto brasileiro de exportação, as mudanças no seu comportamento internacional afetavam sobremaneira os rumos da economia nacional, face à profunda dependência dessa mercadoria. Desse modo, a política monetária nacional reagia ao sabor das oscilações dos preços internacionais do café, resultando em uma dinâmica muito particular no padrão do meio circulante brasileiro no período. Ainda assim, foi possível verificar as retrações na liquidez monetária em momentos relacionados à eclosão das principais crises mundiais. Como a praça da Bahia reclamava da escassez de numerário, informação presente em diversos documentos da época, essa escassez estava relacionada à política monetária mais conservadora, influenciada pelos metalistas, mas também como mecanismo de defesa da economia nacional em relação à instabilidade do sistema internacional no período, sobretudo em função do comportamento da economia norte-americana, o que atrela o comportamento do papel-moeda em poder do público, igualmente, à "Grande Depressão" do século XIX.

No caso específico da Província da Bahia, a avaliação do comportamento de sua balança comercial no período de recessão mundial e doméstica evidencia a simetria entre a piora no comportamento das exportações provinciais e a eclosão das crises de maior importância no cenário internacional. Os próprios movimentos de recuperação nas exportações apontam uma convergência com as oscilações positivas nos preços internacionais ocorridas em intervalos temporais similares. A harmonia entre os dados do comércio exterior provincial e o panorama instável do sistema-mundo no período em análise se constitui numa característica evidente da influência dos efeitos internacionais da "Grande Depressão" sobre a economia da Província da Bahia.

Diante do exposto, observa-se que, tanto a economia brasileira, quanto a baiana, sofreram com os desdobramentos mundiais das crises que ocorreram no período entre 1873 e 1896. A expansão do sistema capitalista de matriz liberal inglesa, gradativamente, amplificava seu raio de ação, incorporando as mais diversas regiões do planeta, inserindo-as na sua dinâmica. A maior ou menor integração ao sistema resultava em efeitos mais ou menos contundentes no âmbito dos respectivos mercados domésticos. Sem se descurar do entendimento de que as particularidades internas 
sempre influenciaram no desempenho das economias nacionais e regionais, o que se verifica é a inclusão de fatores exógenos na compreensão dos quadros tanto brasileiro, quanto baiano, consolidando a interpretação sobre a inserção internacional dos países periféricos e, como consequência desse movimento, a absorção dos efeitos negativos das crises que eclodiam no centro do sistema capitalista com graus de intensidade variados nas esferas nacional e regional.

\section{REFERÊNCIAS}

\section{Fontes primárias}

Falas, mensagens e relatórios dos presidentes da Província da Bahia entre 1872 e 1889. Arquivo Público do Estado da Bahia (APEB). Seção Colonial e Provincial.

Falas, mensagens e relatórios dos governadores da Bahia entre 1890 e 1896. Arquivo Público do Estado da Bahia (APEB). Seção Republicana.

\section{Fontes secundárias}

ARRIGHI, Giovanni. O longo século XX. 5 ed., São Paulo: Contraponto, 2006.

AZEVEDO, Thales de, LINS, E. Q. Vieira. História do Banco da Bahia (1858-1958). Rio de Janeiro: Livraria José Olympio, 1969.

BAHIA. Secretaria de Planejamento, Ciência e Tecnologia. A Inserção da Bahia na Evolução Nacional - 1.a Etapa: 1850-1889 - Atividades Produtivas. Salvador: Fund. Centro de Pesquisas e Estudos - CPE, 1978a.

A Inserção da Bahia na Evolução Nacional - $1^{\text {.a }}$ Etapa: 1850-1889 Atividades Não-Produtivas. Salvador: Fund. Centro de Pesquisas e Estudos - CPE, 1978b.

A Inserção da Bahia na Evolução Nacional - $1^{\text {.a }}$ Etapa: 1850-1889 Anexo Estatístico. Salvador: Fund. Centro de Pesquisas e Estudos - CPE, 1978c.

A Inserção da Bahia na Evolução Nacional: a Bahia no século XIX. Salvador: Fund. Centro de Pesquisas e Estudos - CPE, 1978d.

A Inserção da Bahia na Evolução Nacional - $1^{\text {.a }}$ Etapa: 1850-1889 Agentes Econômicos na Bahia no Século XIX. Salvador: Fund. Centro de Pesquisas e Estudos - CPE, 1979.

A Inserção da Bahia na Evolução Nacional - $1^{\text {.a }}$ Etapa: 1850-1889 -

Comércio. Salvador: Fund. Centro de Pesquisas e Estudos - CPE, 1980. 
BAIROCH, Paul. Economics and world history - myths and paradoxes. Chicago: The University of Chicago Press, 2002.

BEAUD, Michel. História do capitalismo - de 1500 aos nossos dias. São Paulo: Brasiliense, 2004.

CALMON, Francisco Marques de Góes. Vida econômico-financeira da Bahia (18081899). Salvador: Fundação Centro de Pesquisas e Estudos - CPE, 1979.

CALOMIRIS, Charles W., SCHWEIKART, Larry. The panic of 1857: origins, transmission, and containment. The Journal of Economic History, Vol. 51, n. 4, 1991. Disponível em:

<http://apusths.pbworks.com/w/file/fetch/82834207/Panic\%20of\%201857.pdf> Acesso em: 27 de Abr. de 2015.

CHANG, Ha-Joon. Chutando a escada - a estratégia do desenvolvimento em perspectiva histórica. São Paulo: Unesp, 2004.

EICHENGREEN, Barry. A globalização do capital - uma história do sistema monetário internacional. São Paulo: Editora 34, 2000.

FAUSTO, Boris (dir.). O Brasil republicano: estrutura de poder e economia (18891930). 8 ed., Rio de Janeiro: Bertrand Brasil, 2006. (História Geral da Civilização Brasileira; t. e; v.8)

FRIEDEN, Jeffry. Capitalismo global - história econômica e política do século XX. Rio de Janeiro: Jorge Zahar Editor, 2008.

FURTADO, Celso. Formação econômica do Brasil. 16 ed., São Paulo: Companhia Editora Nacional, 1979.

FURTADO, Milton Braga. Síntese da economia brasileira. 6 ed., Rio de Janeiro: Editora LTC, 1998.

GRAHAM, Richard. A Grã-Bretanha e o início da modernização no Brasil (18501914). São Paulo: Editora Brasiliense, 1973.

HOBSBAWM, Eric. Da Revolução Industrial inglesa ao Imperialismo. 4 ed., Rio de Janeiro: Forense Universitária, 1986.

A era do capital. 10 ed., São Paulo: Paz e Terra, 2004.

HOLANDA, Sérgio Buarque de. História geral da civilização brasileira: o Brasil monárquico - declínio e queda do Império. 6 ed., Rio de Janeiro: Bertrand Brasil, 2004. T. II, Vol. 6.

IBGE. Estatísticas históricas do Brasil - séries econômicas, demográficas e sociais de 1550 a 1988. 2 ed., Rio de Janeiro: IBGE, 1990.

KINDLEBERGER, Charles, ALIBER, Robert Z. Manias, pânicos e crises - a história das catástrofes econômicas mundiais. 6 ed., São Paulo: Saraiva, 2013. 
KRIPPENDORFF, Ekkehart. História das relações internacionais. Lisboa: Antídoto, 1979.

LUZ, Nícia Vilela. As tentativas de industrialização no Brasil. In: HOLANDA, Sérgio Buarque de. História geral da civilização brasileira: o Brasil monárquico declínio e queda do Império. 6 ed., Rio de Janeiro: Bertrand Brasil, 2004. T. II, Vol. 6.

MATTOS, Waldemar. Panorama econômico da Bahia (1808-1860). 2 ed., Salvador: Assembleia Legislativa da Bahia, Associação Comercial da Bahia, 2011. (Col.

Comércio Baiano Vol. 3)

MATTOSO, Kátia M. de Queirós. Da Revolução dos Alfaiates à riqueza dos baianos no século XIX - itinerário de uma historiadora. Salvador: Corrupio, 2004.

MAURO, Frédéric. História econômica mundial 1790-1970. 2 ed., Rio de Janeiro: Zahar Editores, 1976.

MELLO, Evaldo Cabral de. O norte agrário e o império 1871-1889. 2 ed., Rio de Janeiro: Topbooks, 1999.

MONT'ALEGRE, Omer. Capital \& capitalismo no Brasil. Rio de Janeiro: Expressão e Cultura, 1972.

OLIVEIRA, Waldir Freitas. História de um Banco: o Banco Econômico. 1.a ed., Salvador: Museu Eugênio Teixeira Leal, 1993.

A Crise da Economia Açucareira do Recôncavo na Segunda Metade do Século XIX. Salvador: CEB/UFBa, n.o 146, 1999.

PRADA, Valentin Vazquez de. História econômica mundial. Porto: Livraria Civilização Editora, 1978. 2 vols.

PELÁEZ, Carlos Manuel, SUZIGAN, Wilson. História monetária do Brasil. 2 ed., Brasília: Editora Universidade de Brasília, 1981. (Col. Temas Brasileiros, 15)

SAMPAIO, Marcos Guedes Vaz. Navegação a vapor na Bahia oitocentista (18391894). Salvador: EDUFBA, 2014.

Uma análise regional sobre as crises de 1857 e 1860: os efeitos na

Província da Bahia. Salvador: Revista de Desenvolvimento Econômico - RDE/

Unifacs, Ano XVIII, vol. 3, n. 35, Dezembro de 2016.

TAVARES, Luís Henrique Dias. História da Bahia. 10 ed., São Paulo:

UNESP/Salvador: EDUFBA, 2001.

WIRTH, Max. The crisis of 1890. Journal of Political Economy, vol. 1, mar. 1893. Disponível em: 〈http://www.journals.uchicago.edu/doi/pdfplus/10.1086/250133>. Acesso em: 20 de Dez. de 2017. 